\title{
Todo está cambiando. Situación de crisis, contexto de oportunidades
}

Hugo Doménech Fabregat Universitat Jaume I

La sección Otras Investigaciones de la revista adComunica en su cuarto número recoge investigaciones y proyectos inéditos con la comunicación como vértice común. El conjunto de artículos presentados en este apartado se encuentran estrechamente vinculados a un contexto comunicativo cambiante propio de una coyuntura de crisis y una revolución tecnológica como aspectos más destacados.

En muchas ocasiones se constata que las circunstancias vigentes son aprovechadas por las empresas y grupos de comunicación para realizar ajustes a la baja tanto en la calidad de sus contenidos como en la situación laboral de los propios trabajadores del medio. Sin embargo, la otra cara de la moneda de la actual coyuntura comunicativa también proyecta nuevos modelos de negocio, perfiles profesionales o estrategias publicitarias.

En definitiva, estas otras investigaciones que aquí se exponen son un reflejo evidente de la variedad de procesos y tendencias que a día de hoy invitan a la reflexión sobre el escenario comunicativo tanto presente como futuro.

En un primer artículo titulado Presencia y participación de trabajadores y colaboradores en las emisoras de radio locales y comarcales en Cataluña, los profesores Sergi Solà y Josep Lluís Micó estudian la vertiente humana y laboral en las radios locales y comarcales en un territorio donde este medio tiene un desarrollo y arraigo histórico importante. El trabajo defiende el factor humano como un elemento diferencial en los medios locales y que particularmente nos puede servir para comprender la realidad de la radio de proximidad. 
Precisamente, la investigación tiene como objetivo prioritario establecer la incidencia y aportación real de la vertiente humana en un modelo concreto de comunicación. Para dar respuesta a este propósito los autores parten de la definición y caracterización de las figuras del trabajador en plantilla y de los colaboradores para, a continuación, determinar una taxonomía funcional de ambas figuras en la radio local catalana. Un segundo propósito del análisis de situación planteado consiste en la exploración de qué figura predomina y qué responsabilidades asumen tanto los profesionales como los colaboradores. Este estudio de la realidad laboral de los medios de comunicación en Cataluña determina que no existe una figura imprescindible e incide en la necesidad de profundizar en el análisis profesional.

El segundo estudio, Universidad y empresa ante la doble crisis del periodismo tradicional. Propuestas y reflexiones sobre la modificación sustancial del escenario periodístico. El clúster periodístico, elaborado por Fernando Sabés y José Juan Verón, parte de una premisa contrastada: cuando la situación de la profesión periodística sufre una profunda crisis de modelo de negocio y credibilidad, los estudios de periodismo continúan siendo uno de los preferidos por los estudiantes universitarios españoles. Esta realidad sirve de punto de partida a los autores para argumentar en torno al futuro del sector periodístico y el papel de las universidades en la formación de los futuros profesionales.

Entre otros aspectos, el estudio analiza el cambio radical que ha supuesto la consolidación de Internet como soporte de transmisión de contenidos informativos y los modos de consumo del público, para posteriormente abordar una cuestión clave: ¿cómo ha variado la formación de los futuros periodistas? Las respuestas que aportan los profesores Sabés y Verón son claras y directas. Entre otras reflexiones, inciden en que la Universidad y la profesión deberían trabajar conjuntamente por una aproximación real que reconociera que, pese a las necesarias adaptaciones de modelo de negocio y tecnológicas, la instrucción de los alumnos debería seguir fomentando como prioridad insoslayable la formación en conceptos y principios profesionales sólidos.

De igual forma, el artículo invita a las universidades españolas a convertirse en auténticos laboratorios de experiencias de emprendeduría que ofrezcan servicios de comunicación. Así los autores reivindican la creación de clusters periodísticos vinculados a un territorio o ámbito, con el fin de aunar fuerzas que permitieran asumir retos más ambiciosos y, en definitiva, trabajaran por recuperar la debilitada confianza de la sociedad hacia el periodismo.

Desde un ámbito contiguo al periodismo se presenta un trabajo centrado en las relaciones públicas. Gloria Jiménez, Marta Pulido y Carmen Silva exploran en su análisis Label de calidad e indicaciones geográficas protegidas como estrategia empresarial: el caso Brandy de Jerez desde una perspectiva de las RR.PP.; el valor añadido que aporta un sello de calidad como elemento clave en la gestión de la comunicación de un producto agroalimentario como el vino. 
Partiendo de la reflexión sobre la funcionalidad de las indicaciones geográficas protegidas como base fundamental de la gestión estratégica, el artículo reconoce que la adopción de estas etiquetas de protección permite a los sectores productivos implicados, la comunicación de unos valores positivos canalizados en torno a la percepción de la calidad de sus productos. El estudio de caso sobre indicación geográfica protegida Brandy de Jerez se sirve de variadas herramientas de análisis como la entrevista, la observación directa o la consulta de fuentes de datos secundarios.

Por último, la sección Otras Investigaciones se cierra con la presentación de un directorio especializado sobre estudios fílmicos pergeñado por el profesor Ricardo Albiñana, y que supone un ejemplo significativo de fuente informativa estructurada y especializada. La web http://www.comunicacioninvisible.net cumple la función de clasificar y vincular las diferentes webs disgregadas en Internet en relación a la cuestión cinematográfica. Esta página académica está compuesta por la información almacenada en bases de datos disponible dinámica y públicamente en Internet, que no es recuperada por los buscadores convencionales, es decir, no indexada por éstos, y accesible únicamente interrogando los formularios de búsqueda de cada base de datos. La clasificación temática para la búsqueda de recursos fílmicos incluye desde críticas, guiones de cine hasta aspectos históricos y culturales relacionados con este ámbito temático.

\section{Referencia de este artículo}

Domènech Fabregat, Hugo (2012). Todo está cambiando. Situación de crisis, contexto de oportunidades. En: adComunica. Revista Científica de Estrategias, Tendencias e Innovación en Comunicación, $\mathrm{n}^{0}$ 4. Castellón: Asociación para el Desarrollo de la Comunicación adComunica, Universidad Complutense de Madrid y Universitat Jaume I, 121-123. DOI: http://dx.doi.org/10.6035/21740992.2012.4.8 